\title{
Pharmacokinetics, safety and tolerability of three dosage regimens of buccal adhesive testosterone tablets in healthy men suppressed with leuprorelin
}

\author{
K J Baisley, M J Boyce, S Bukofzer ${ }^{1}$, R Pradhan ${ }^{1}$ \\ and $\mathbf{S} \mathbf{J}$ Warrington \\ Hammersmith Medicines Research, Central Middlesex Hospital, London NW10 7NS, UK \\ ${ }^{1}$ Abbott Laboratories, 200 Abbott Park Road, Abbott Park, Illinois 60064, USA \\ (Requests for offprints should be addressed to M J Boyce; Email: mboyce@hmrlondon.com)
}

\begin{abstract}
We used a randomised, double-blind, crossover design to evaluate the pharmacokinetics, safety and tolerability of three doses of buccal adhesive testosterone tablets (BATT). Twenty-four healthy men, whose endogenous testosterone was suppressed to $\leq 5.38 \mathrm{nmol} / 1$ with leuprorelin acetate, took BATT (10, 20 or $30 \mathrm{mg})$ daily for 10 days. There was a 4-day washout between treatments. Substantial testosterone absorption occurred from BATT, and mean serum testosterone, free testosterone and dihydrotestosterone (DHT) concentrations over $24 \mathrm{~h}$ showed circadian variation. Steady state was reached by
\end{abstract}

day 5. Average 24-h concentrations for the three BATT doses were within the normal range for eugonadal men: testosterone $11 \cdot 67-14.57 \mathrm{nmol} / 1$, free testosterone $0 \cdot 026-$ $0 \cdot 33 \mathrm{nmol} / 1$ and DHT $1 \cdot 66-2 \cdot 03 \mathrm{nmol} / 1$. On all three doses, peak testosterone and free testosterone was reached 8-9 h after tablet application; DHT peaked about 1-2 h later, and declined more slowly. Hormone concentrations increased with BATT dose, but increases were less than dose-proportional. There was no evidence of testosterone accumulation. BATT was well tolerated.

Journal of Endocrinology (2002) 175, 813-819

\section{Introduction}

Testosterone, the main circulating androgen in men, is secreted predominantly by the testes. Normal serum testosterone concentrations are $10 \cdot 41-34 \cdot 70 \mathrm{nmol} / \mathrm{l}$, and show circadian variation with peak concentrations in the morning (Bremner et al. 1983, Place \& Nichols 1991). In extragonadal tissues, circulating testosterone is enzymatically converted to dihydrotestosterone (DHT) by $5 \alpha$-reductase.

The main indication for androgen replacement therapy in men is primary or secondary hypogonadism associated with a deficiency of endogenous testosterone (Bhasin 1992, Snyder et al. 2000). The restoration of testosterone concentrations to normal maintains or induces male secondary sexual characteristics, sexual behaviour, energy, mood and muscle development (Matsumoto 1994, Dobs et al. 1999, Wang et al. 2000b, Basaria \& Dobs 2001). Various exogenous testosterone formulations have been developed, including injectable, oral and dermal preparations. Intramuscular injections often yield testosterone concentrations greatly above normal during the first few days after administration, and do not produce daily variation in testosterone concentrations (Behre et al. 1994, Matsumoto 1994, Dobs et al. 1999). Oral testosterone undecanoate, used in Europe, is a lipid-soluble preparation that is absorbed directly into the lymphatic system, thereby avoiding first-pass metabolism in the liver (Conway et al. 1988). However, because of the poor oral bioavailability of testosterone, the levels of circulating testosterone obtained with such treatment are unpredictable (Cantrill et al. 1984, Conway et al. 1988, Bagatelle \& Bremner 1996). Transdermal delivery of testosterone, widely prescribed in the USA as either a patch or gel, can yield physiological concentrations of testosterone, and a circadian pattern close to that of healthy men (Meikle et al. 1996, Dobs et al. 1999). Transdermal patches often cause local skin reactions (Arver et al. 1997, Parker \& Armitage 1999), and the scrotal patch produces very high concentrations of DHT, owing to high $5 \alpha$-reductase activity in scrotal skin (Cunningham et al. 1989, Meikle et al. 1992). Testosterone gel causes only minimal skin irritation (Wang et al. 2000a), but it must be applied over a large surface area of skin (Wang et al. 2000a,b), and thus may not be acceptable to all patients.

In this study, we evaluated the pharmacokinetics, tolerability and safety of three dosage strengths of a buccal adhesive testosterone tablet (BATT), under development by Abbott Laboratories (Abbotts Park, IL, USA). Buccal administration 'bypasses' the liver and so avoids first-pass 
clearance (Dobs et al. 1998). To study BATT, we used a model of artificial hypogonadism in healthy men, by temporarily suppressing their endogenous testosterone secretion with a gonadotrophin-releasing hormone agonist, leuprorelin acetate (Linde et al. 1981, Frick \& Aulitzky 1986, Leibenluft et al. 1997). We evaluated serum testosterone, free testosterone and DHT concentrations on 10, 20 and $30 \mathrm{mg}$ BATT.

\section{Materials and Methods}

\section{Subject population}

Our subjects were twenty-four healthy men, aged 22-66 years (mean $=37.5$ years; S.D. $=12.5$ years), body mass index $21 \cdot 1-31 \cdot 8 \mathrm{~kg} / \mathrm{m}^{2} \quad\left(\right.$ mean $=25.2 \mathrm{~kg} / \mathrm{m}^{2} ; \quad$ S.D. $=$ $2 \cdot 7 \mathrm{~kg} / \mathrm{m}^{2}$ ). Twenty-two subjects were Caucasian, one was Black and one was Asian. All were deemed healthy by medical history and examination, standard 12-lead electrocardiogram (ECG) and clinical laboratory tests, including morning serum testosterone. Mean testosterone concentration was $18 \cdot 89 \mathrm{nmol} / 1$ (range $11 \cdot 00-34 \cdot 98$ ).

The study complied with the Declaration of Helsinki and the protocol was approved by the local ethics committee. All subjects gave fully informed, written consent.

\section{Study design}

The study was a randomised, double-blind, three-way crossover comparison of multiple doses of identical tablets of BATT $(10,20$ and $30 \mathrm{mg})$ in healthy men whose endogenous testosterone secretion had been suppressed with leuprorelin. It consisted of four consecutive phases: screening, baseline, treatment and follow-up. During the screening phase, subjects received two to three injections of $3.75 \mathrm{mg}$ leuprorelin acetate (Wyeth, Maidenhead, Berks, UK), 3 weeks apart, to suppress their endogenous testosterone, and took androgen replacement therapy (oral testosterone undecanoate; Organon, Oss, The Netherlands). We measured their morning serum testosterone for 3 weeks, at 1 -week intervals, starting 1 week after their second leuprorelin injection. Subjects stopped testosterone replacement therapy $\geq 48 \mathrm{~h}$ before we evaluated their serum testosterone. Those whose morning testosterone had fallen to $\leq 5.38 \mathrm{nmol} / 1$ were randomised, and entered the baseline and treatment phases of the study.

During the baseline phase (day -1$)$, all subjects received one placebo tablet identical to the BATT tablets. The treatment phase consisted of three periods, during which we evaluated the pharmacokinetics, safety and tolerability of the BATT. The periods each lasted 10 days, and were separated by 4-day washouts. We gave all subjects a third injection of leuprorelin $(3.5 \mathrm{mg})$ on day 10 of the first period, after the 24-h blood collection.

In the follow-up phase, which began 1 day after the last BATT dose, we measured subjects' morning serum testosterone every 2 weeks, until in the normal range. Subjects took oral testosterone undecanoate, but stopped taking it $\geq 48 \mathrm{~h}$ before we measured their serum testosterone.

\section{BATT treatment}

Subjects applied the BATT to the gingiva, in the region of the infranasal fossa, at $0800 \mathrm{~h}$ each day, for 10 consecutive days. They were asked to eat breakfast and brush their teeth before applying BATT, and to avoid drinking for 30 min afterwards.

Subjects were resident from $12 \mathrm{~h}$ before to $24 \mathrm{~h}$ after dosing, during the baseline phase, and on days 1 and 10 of each period. On days 5-9, subjects attended each morning for pre-dose blood samples, then applied BATT.

\section{Hormone assays}

We measured testosterone, free testosterone and DHT in serum samples taken at the following times: before dosing and $1 \cdot 5,3,4,5,6,8,12,15,18$ and $24 \mathrm{~h}$ after dosing on day -1 (baseline phase) and on days 1 and 10 of each period, before dosing on days 5-9 of each period.

Serum was separated and stored at $-20^{\circ} \mathrm{C}$ or below until assayed. Hormone concentrations were measured by validated, radioimmunological assays (RIA) using kits from Diagnostic Systems Laboratories, Inc. (Webster, TX, USA). Lower limits of quantitation were $0.35 \mathrm{nmol} / 1$ (testosterone), $0.001 \mathrm{nmol} / 1$ (free testosterone) and 0.09 nmol/l (DHT). Intra-assay and interassay coefficients of variation for all assays were $<9 \%$ and $<12 \%$ respectively.

RIA is not as good as equilibrium dialysis for measuring absolute concentrations of free testosterone. However, with respect to free testosterone, we were mainly concerned with relative concentrations on different doses of BATT, so we believe the method to be adequate for our purposes.

\section{Pharmacokinetic analyses}

For all BATT doses, we determined the following pharmacokinetic parameters of each hormone: maximum concentration $\left(\mathrm{C}_{\max }\right)$, minimum concentration $\left(\mathrm{C}_{\min }\right)$, time of maximum concentration $\left(\mathrm{t}_{\max }\right)$, area under the concentration curve from 0 to $24 \mathrm{~h}\left(\mathrm{AUC}_{0-24}\right)$, and time-average concentration $\left(\mathrm{C}_{\mathrm{avg}}\right.$, equal to $\left.\mathrm{AUC}_{0-24} / 24\right)$.

In addition, we calculated baseline-adjusted pharmacokinetic parameters for each hormone, by subtracting the subject's baseline (day -1) serum concentrations from the corresponding concentrations on days 1 and 10 . We obtained baseline-adjusted $\mathrm{AUC}_{0-24}$ by deducting the subject's baseline $\mathrm{AUC}_{0-24}$ from the observed $\mathrm{AUC}_{0-24}$. 
Lastly, we calculated free testosterone/testosterone and testosterone/DHT ratios, using the baseline-adjusted concentrations of each hormone.

\section{Safety and tolerability assessments}

We assessed BATT safety and tolerability by: dental assessment, ECG, vital signs, physical examination and laboratory safety tests before and after dosing, and by adverse events.

In addition, we examined the subject's gingiva and lip mucosa before and $12 \mathrm{~h}$ after BATT application, at baseline (day -1), and on days 1 and 10 of each treatment period. Subjects were also asked to assess tablet acceptability and tolerability.

\section{Statistical analyses}

Baseline-adjusted pharmacokinetic parameters of each hormone were used in all statistical analyses; $\mathrm{C}_{\max }$ and $\mathrm{AUC}_{0-24}$ were $\log$ transformed. Significance was evaluated at the level of $P<0 \cdot 05$.

To test for dose proportionality, we did an analysis of variance (ANOVA) of the dose-normalised pharmacokinetic parameters of each hormone, using PROC GLM (SAS version 6.12; SAS Institute, Cary, NC, USA). To test for BATT accumulation, we compared $\mathrm{t}_{\max }, \mathrm{C}_{\max }$ and $\mathrm{AUC}_{0-24}$ of each hormone between days 1 and 10, by a linear mixed effect analysis using PROC MIXED (SAS Institute). Initial models contained fixed effects for sequence, period and dose, and carryover from the dose of the preceding period, and random effects for subject nested within sequence. If carryover effects were not significant, they were dropped from the model. The morning pre-dose concentrations of each hormone $\left(\mathrm{C}_{\mathrm{min}}\right)$ were analysed in the same manner, to assess when steady state had been reached.

To investigate the possibility of an age effect on the pharmacokinetic parameters of each hormone, we did an additional ANOVA on the mean of each parameter for all three treatment periods, with fixed effects for age, body weight and sequence.

Safety and tolerability data were summarised by frequency counts or summary statistics, as appropriate; no formal statistical testing was done.

\section{Results}

\section{Suppression of subjects with leuprorelin acetate}

During the screening phase, subjects received 7.25$11.25 \mathrm{mg}$ leuprorelin acetate over 4-6 weeks. Morning serum testosterone was suppressed to $\leq 5.38 \mathrm{nmol} / 1$ $($ mean $=2.34 ;$ s.D. $=1.60)$. During the follow-up phase, serum testosterone returned to the normal range in all subjects $(10 \cdot 41-34 \cdot 70 \mathrm{nmol} / \mathrm{l})$.

\section{Pharmacokinetics of BATT}

Mean serum testosterone, free testosterone and DHT concentrations over $24 \mathrm{~h}$ were similar on the three doses of BATT (Fig. 1). At steady state, all BATT doses produced an early increase in mean testosterone and free testosterone, with maximum concentrations about 8-9 h after tablet application, and a slow decline thereafter. DHT concentrations peaked about $2 \mathrm{~h}$ later, and declined more gradually, than those of testosterone and free testosterone.

Summary statistics of the baseline-adjusted pharmacokinetic parameters of each hormone are shown in Table 1. Mean pre-dose testosterone, free testosterone and DHT did not differ significantly between successive days, on days $5-9$, indicating that steady state had been reached by day 5. At steady state, mean $\mathrm{C}_{\max }$ and $\mathrm{AUC}_{0-24}$ of each hormone increased with dose. However, dose-normalised, mean $\mathrm{C}_{\max }$ and $\mathrm{AUC}_{0-24}$ of each hormone were significantly lower in the $30 \mathrm{mg}$ than in the $10 \mathrm{mg}$ dose group, on both day 1 and day $10(P<0 \cdot 001)$. Thus, the increase in testosterone, free testosterone and DHT was less than dose-proportional.

In the 20 and $30 \mathrm{mg}$ dose groups, mean $\mathrm{C}_{\max }$ and $\mathrm{AUC}_{0-24}$ of each hormone were higher on day 1 than on day 10 , indicating that none of the hormones accumulated. Furthermore, mean $t_{\max }$ and dose-normalised $\mathrm{AUC}_{0-24}$ of testosterone and free testosterone, and $\mathrm{t}_{\max }$ of DHT, were significantly lower on day 10 than on day $1(P=0.02$ to $<0 \cdot 001)$. Age had no statistically significant effect on mean baseline-adjusted pharmacokinetic parameters of testosterone, free testosterone or DHT $(P=0.06$ to 0.96$)$. Carryover effects were not significant in most of the statistical analyses.

$\mathrm{C}_{\mathrm{avg}}$ of testosterone, free testosterone and DHT are shown in Fig. 2, with the associated normal ranges. Hormone concentrations were within the normal range in most subjects on all BATT doses. Free testosterone/ testosterone ratios averaged about $0 \cdot 02$, on all BATT doses, and on placebo. On the 10 and $20 \mathrm{mg}$ tablets, average testosterone/DHT ratios were between 4 and 14 during the $24 \mathrm{~h}$ after dosing, compared with 4 to 8 on placebo. However, on BATT $(30 \mathrm{mg})$, average testosterone/DHT ratios fluctuated more widely with time, ranging between 3 and 23 .

Although $\mathrm{C}_{\mathrm{avg}}$ of testosterone was $<34.70 \mathrm{nmol} / 1$ in all subjects, concentrations in some blood samples were supraphysiological. Testosterone concentrations were $>41.64 \mathrm{nmol} / 1$ in at least one blood sample in three subjects on BATT $(20 \mathrm{mg})$, and in five subjects on BATT $(30 \mathrm{mg})$. DHT concentrations were $>3 \cdot 45 \mathrm{nmol} / 1$ in at least one blood sample in six, eleven and thirteen subjects on $\operatorname{BATT}(10,20$ and $30 \mathrm{mg})$ respectively. In most 

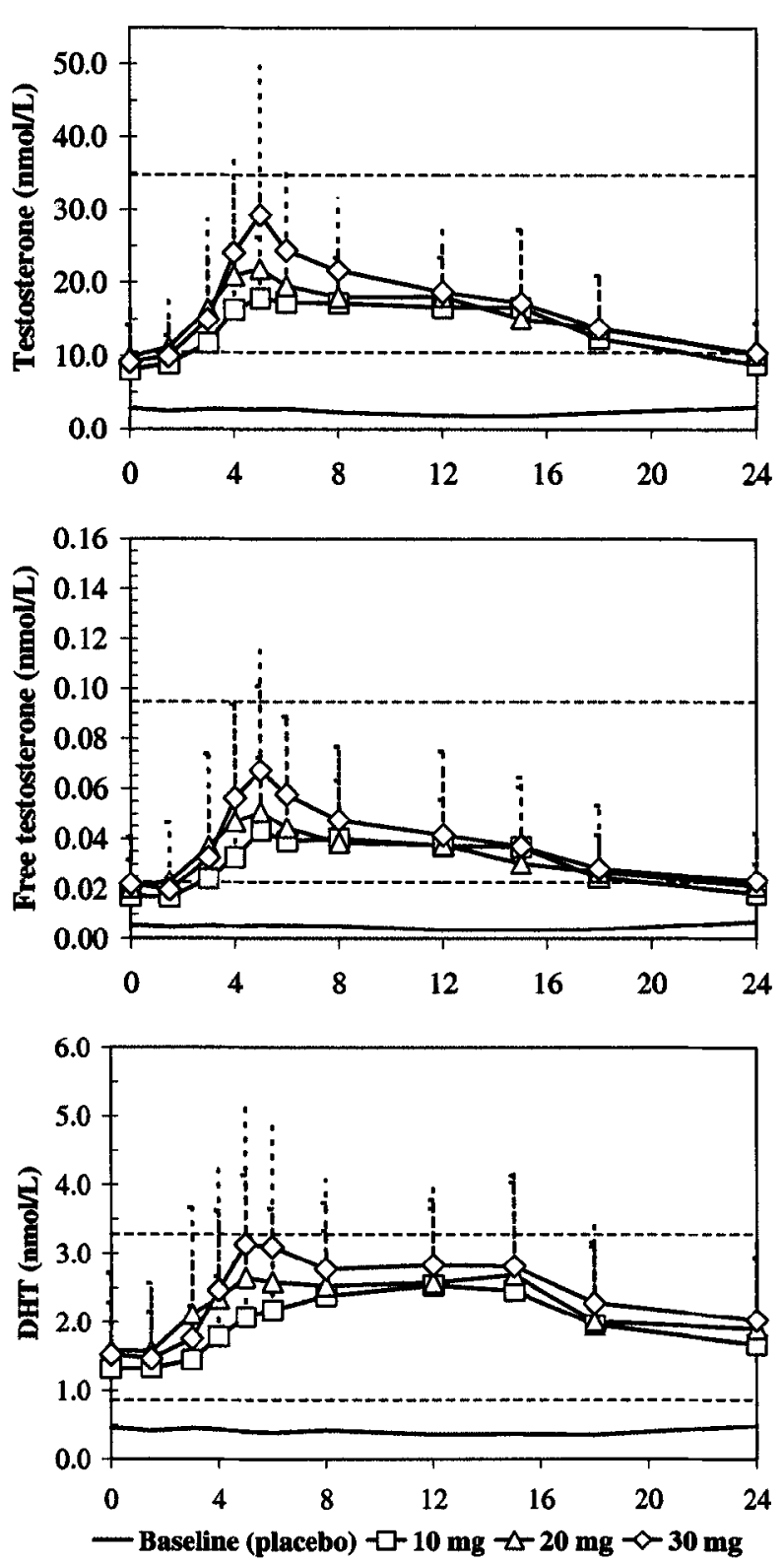

Figure 1 Mean, baseline-adjusted serum concentrations of testosterone, free testosterone and DHT on the three dose regimens of BATT over $24 \mathrm{~h}$, at steady state (day 10 of dosing). Time (h) is on the $x$ axis. Vertical broken lines are S.D. and horizontal broken lines represent normal ranges for eugonadal men (testosterone: $10 \cdot 41-34 \cdot 70 \mathrm{nmol} / \mathrm{l}$; free testosterone: 0.023-0.095 nmol/l; DHT: 0.86-3.28 nmol/l).

subjects, such high hormone concentrations were observed at about two to four sampling times.

\section{Safety and tolerability}

There were no clinically significant changes in vital signs, physical examination, ECG or laboratory safety values.
Minor adverse events were experienced by several subjects; however, none was considered to be related to treatment.

Localised hyperaemia at the BATT application site was noted in two subjects on day 10 of the last treatment period. Thirteen and twelve subjects reported local discomfort on BATT and placebo respectively; most subjects experienced that discomfort in the first treatment period.

\section{Discussion}

Leuprorelin successfully minimised fluctuations of endogenous testosterone and suppressed concentrations to $\leq 5.38 \mathrm{nmol} / \mathrm{l}$ in all subjects, so that exogenous hormone concentrations could be reliably measured with little interference from endogenous testosterone. A similar method has been used successfully to study transdermal testosterone (Rolf et al. 1999). However, endogenous testosterone secretion might have recovered partially before the end of the study. We minimised that possibility by giving an additional injection of leuprorelin, which suppresses testosterone for 4 weeks (Physician's Desk Reference 2000), at the end of the first treatment period. Morning testosterone was still below the lower limit of normal at first follow-up, although it returned to normal subsequently. Thus, we believe there was little interference from endogenous testosterone in our assessment of the performance of BATT.

The pharmacokinetic data showed that substantial testosterone absorption occurred after BATT administration in all twenty-four subjects. On all three dosage regimens, testosterone, free testosterone and DHT increased soon after tablet application, and remained above baseline for at least $24 \mathrm{~h}$. By day 5 , the first sampling day after the initial 24-h blood collection on day 1, steady state had already been reached. Therefore, it is likely that steady state was achieved soon after BATT was started. In contrast, testosterone replacement therapy with intramuscular injections or some transdermal patches may require several weeks of use before steady state is reached (Place \& Nichols 1991, Yu et al. 1997).

Androgen replacement therapy in hypogonadal men seeks to provide near-physiological circulating concentrations of testosterone and its active metabolites, and to mimic the diurnal pattern seen in healthy men (Bhasin 1992, Snyder et al. 2000). On all three doses of BATT, 24-h average concentrations of testosterone, free testosterone and DHT were in the normal range in most subjects. Supraphysiological concentrations of testosterone occurred in only a few blood samples ( $<3 \%$ above $38.17 \mathrm{nmol} / 1$, maximum $=74.61 \mathrm{nmol} / \mathrm{l}$ ) in some subjects on the 20 and $30 \mathrm{mg}$ doses, and never reached the concentrations reported after intramuscular testosterone (Cunningham et al. 1989, Dobs et al. 1999). In addition, testosterone/ DHT ratios were generally within the normal range 
Table 1 Mean (S.D.) baseline-adjusted pharmacokinetic parameters for each hormone on 10,20 and 30 mg BATT at steady state (day 10 of dosing)

\begin{tabular}{|c|c|c|c|}
\hline & $10 \mathrm{mg}$ & $20 \mathrm{mg}$ & $30 \mathrm{mg}$ \\
\hline \multicolumn{4}{|l|}{ Parameter } \\
\hline \multicolumn{4}{|c|}{ Testosterone $(\mathrm{nmol} / \mathrm{l})$} \\
\hline$A \cup C_{0-24}$ & $279.96(125 \cdot 06)$ & $315 \cdot 60(96 \cdot 88)$ & $349 \cdot 81(147 \cdot 72)$ \\
\hline $\mathrm{C}_{\max }$ & $23 \cdot 28(7 \cdot 98)$ & $27.62(11.94)$ & $32 \cdot 20(17 \cdot 94)$ \\
\hline $\mathrm{C}_{\min }$ & $3 \cdot 57(4 \cdot 37)$ & $3 \cdot 33(3 \cdot 19)$ & $3 \cdot 33(4.58)$ \\
\hline$t_{\max }$ & $9 \cdot 5(5 \cdot 3)$ & $9 \cdot 1(6 \cdot 3)$ & $8 \cdot 2(5 \cdot 3)$ \\
\hline \multicolumn{4}{|c|}{ Free testosterone $(\mathrm{nmol} / \mathrm{l})$} \\
\hline $\mathrm{AUC}_{\mathrm{O}-24}$ & $0.615(0.347)$ & $0 \cdot 668(0 \cdot 254)$ & $0.779(0.396)$ \\
\hline $\mathrm{C}_{\max }$ & $0.057(0.029)$ & $0.064(0.035)$ & $0.077(0.045)$ \\
\hline $\mathrm{C}_{\min }$ & $0.007(0.009)$ & $0.006(0.006)$ & $0.007(0.009)$ \\
\hline$t_{\max }$ & $8 \cdot 6(4 \cdot 7)$ & $8 \cdot 7(5 \cdot 9)$ & $7 \cdot 8(4 \cdot 9)$ \\
\hline \multicolumn{4}{|c|}{ DHT (nmol/l) } \\
\hline $\mathrm{AUC}_{0-24}$ & $39 \cdot 80(21 \cdot 17)$ & $45 \cdot 72(20 \cdot 32)$ & $48 \cdot 78(21 \cdot 17)$ \\
\hline $\mathrm{C}_{\max }$ & $2 \cdot 95(1 \cdot 30)$ & $3.55(1.50)$ & $3.93(1 \cdot 71)$ \\
\hline $\mathrm{C}_{\min }$ & $0 \cdot 60(0 \cdot 71)$ & $0.62(0.51)$ & $0.59(0.70)$ \\
\hline$t_{\max }$ & $12 \cdot 4(6 \cdot 4)$ & $9 \cdot 8(6 \cdot 9)$ & $9 \cdot 7(5 \cdot 9)$ \\
\hline
\end{tabular}

(Meikle et al. 1992), and fluctuated only modestly over $24 \mathrm{~h}$ on BATT (10 and $20 \mathrm{mg}$ ).

Hormone concentrations on BATT showed diurnal fluctuation, with steady-state testosterone and free testosterone concentrations peaking about $9 \mathrm{~h}$ after tablet application, and declining slowly thereafter. DHT concentrations peaked several hours later than did testosterone, and declined more slowly. Our results indicate that release and absorption of testosterone from BATT must continue for some hours after the tablet is applied. The later peak and slower decline of DHT concentrations have been reported with other testosterone replacement systems (Meikle et al. 1996, Dobs et al. 1998), and can be attributed to continued metabolite formation as testosterone declines, and to the somewhat longer half-life of DHT.

The mean concentrations of all three hormones increased with BATT dose, although that increase was less than dose-proportional. No accumulation of testosterone was noted with repeated doses of BATT. In fact, on all three doses, mean testosterone and free testosterone were lower at steady state than on day 1, suggesting that the rate of testosterone elimination might have increased, or bioavailability decreased, at steady state. There was large intersubject variability in the serum concentrations of each hormone, even after steady state had been reached and, in some subjects, hormone concentrations decreased with BATT dose. Studies of transdermal patches (Brocks et al. 1996) and of testosterone gel (Wang et al. 2000a) in hypogonadal men also show high variability among subjects, and failure of serum testosterone concentrations to increase with dose in some subjects.

Dobs et al. (1998), in their study of a different buccal testosterone preparation in thirteen hypogonadal men, noted diurnal fluctuations of testosterone, free testosterone and DHT concentrations, and found no evidence of hormone accumulation over time. However, although testosterone/DHT ratios were in the normal range, the authors observed much higher testosterone (mean $\mathrm{C}_{\max }=96.81$ vs $23.28 \mathrm{nmol} / \mathrm{l}$ ) and DHT concentrations (mean $\mathrm{C}_{\max }=3.79$ vs $2.95 \mathrm{nmol} / \mathrm{l}$ ) on a $10 \mathrm{mg}$ dose than we did. Thus, BATT seems to yield more physiological concentrations of those hormones.

Studies of $100 \mathrm{mg}$ testosterone gel report average 24-h testosterone concentrations at steady state that are roughly double those that we observed on the three BATT dosages (Wang et al. 2000a,b), and mean $\mathrm{C}_{\min }$ that is much higher on gel than on BATT. Also, the ratio of mean peak:trough testosterone concentrations on gel was about 2, whereas on BATT it was about 10. However, it remains to be studied whether those differences have any clinical consequences.

Our results suggested that there is an upper limit to the rate of absorption of testosterone from BATT, across a given area of gingival mucosa: a smaller proportion of the testosterone content was absorbed from the higher doses of BATT than from the $10 \mathrm{mg}$ tablet. Furthermore, there was no appreciable difference between the $20 \mathrm{mg}$ and $30 \mathrm{mg}$ dose groups with respect to $\mathrm{C}_{\mathrm{avg}}$ of any hormone. If our results are indeed explained by rate-limited absorption across the gingival mucosa, then the proportion of dose that is absorbed might be improved by applying BATT over a wider area. Two $\times 10 \mathrm{mg}$ tablets or two $\times 20 \mathrm{mg}$ tablets, for example, might yield higher bioavailability than would single tablets containing the same dose.

BATT was well tolerated. As many subjects experienced discomfort from placebo as from BATT. Most subjects who reported discomfort did so during the first 

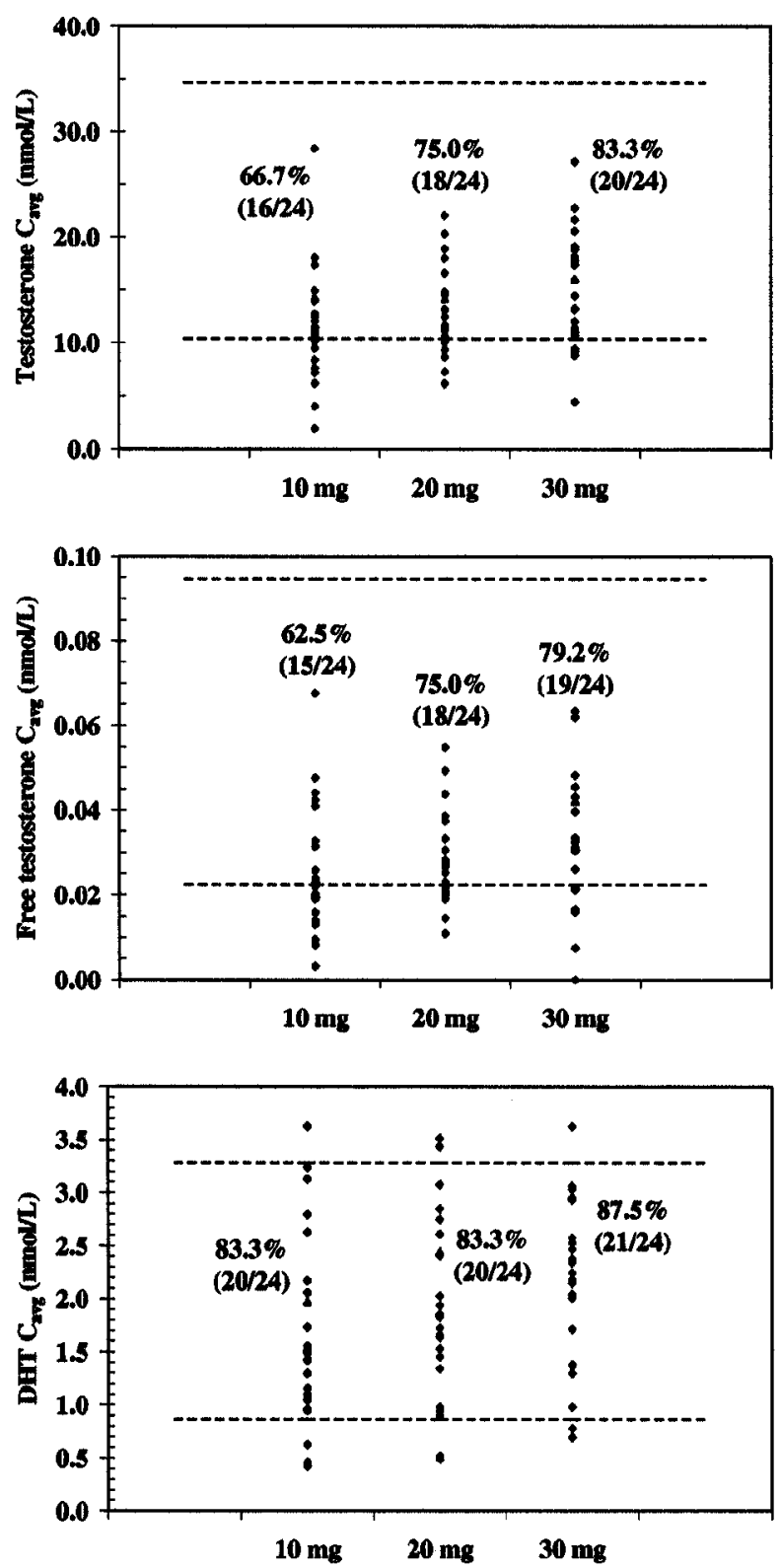

Figure 2 Baseline-adjusted $24 \mathrm{~h}$ average concentrations $\left(\mathrm{C}_{\mathrm{avg}}\right)$ of each hormone on the three dose regimens of BATT ( $x$ axis), with the number and percentage of subjects in the normal range. All hormone concentrations are at steady state (day 10 of dosing). Broken lines represent normal ranges for eugonadal men.

treatment period only, suggesting that discomfort was due to unfamiliarity with the tablet.

In summary, physiological concentrations of testosterone, free testosterone and DHT were reached on all three doses of BATT, and a circadian rhythm in hormone concentrations was produced. Steady state was rapidly attained, and hormone levels quickly returned to baseline after tablet removal. Furthermore, BATT was well tolerated. Studies in hypogonadal men are warranted.

\section{References}

Arver S, Dobs AS, Meikle AW, Caramelli KE, Rajaram L, Sanders SW \& Mazer NA 1997 Long-term efficacy and safety of a permeation-enhanced testosterone transdermal system in hypogonadal men. Clinical Endocrinology 47 727-737.

Bagatelle CJ \& Bremner WJ 1996 Androgens in men: uses and abuses. New England Journal of Medicine 334 707-714.

Basaria S \& Dobs AS 2001 Hypogonadism and androgen replacement therapy in elderly men. American Journal of Medicine 110 563-572.

Behre HM, Baus S, Kliesch S, Keck C, Simoni M \& Nieschlag E 1995 Potential of testosterone buciclate for male contraception: endocrine differences between responders and nonresponders. Journal of Clinical Endocrinology and Metabolism 80 2394-2403.

Bhasin S 1992 Clinical review: androgen treatment of hypogonadal men. Journal of Clinical Endocrinology and Metabolism 74 1221-1225.

Bremner WJ, Vitiello MV \& Prinz PN 1983 Loss of circadian rhythmicity in blood testosterone levels with aging in normal men. Journal of Clinical Endocrinology and Metabolism 56 1278-1281.

Brocks DR, Meikle AW, Boike SC, Mazer NA, Zariffa N, Audet PR \& Jorkasky DK 1996 Pharmacokinetics of testosterone in hypogonadal men after transdermal delivery: influence of dose. Journal of Clinical Pharmacology 36 732-739.

Cantrill J, Dewis P, Large DM, Newman M \& Anderson DC 1984 Which testosterone replacement therapy? Clinical Endocrinology 21 97-107.

Conway AJ, Boylan LM, Howe C, Ross G \& Handelsman DJ 1988 Randomized clinical trial of testosterone replacement theory in hypogonadal men. International Journal of Andrology 11 247-264.

Cunningham GR, Cordero E \& Thornby JI 1989 Testosterone replacement with transdermal therapeutic systems: physiological serum testosterone and elevated dihydrotestosterone levels. Journal of the American Medical Association 261 2525-2530.

Dobs AS, Hoover DR, Chen MC \& Allen R 1998 Pharmacokinetic characteristics, efficacy, and safety of buccal testosterone in hypogonadal males: a pilot study. Journal of Clinical Endocrinology and Metabolism 83 33-39.

Dobs AS, Meikle AW, Arver S, Sanders SW, Caramelli KE \& Mazer NA 1999 Pharmacokinetics, efficacy, and safety of a permeation-enhanced testosterone transdermal system in comparison with bi-weekly injections of testosterone ethanate for the treatment of hypogonadal men. Journal of Clinical Endocrinology and Metabolism 84 3469-3478.

Frick J \& Aulitzky W 1986 Effects of a potent LHRH-agonist on the pituitary gonadal axis with and without testosterone substitution. Urological Research 14 261-264.

Leibenluft E, Schmidt PJ, Turner EH, Danaceau MA, Ashman SB, Wehr TA \& Rubinow DR 1997 Effects of leurolide-induced hypogonadism and testosterone replacement on sleep, melatonin and prolactin secretion in men. Journal of Clinical Endocrinology and Metabolism 82 3203-3207.

Linde R, Doelle GC, Alexander N, Kirchner F, Vale W, Rivier J \& Rabin D 1981 Reversible inhibition of testicular steroidogenesis and spermatogenesis by a potent gonadotropin-releasing hormone agonist in normal men. New England Journal of Medicine 305 663-667.

Matsumoto AM 1994 Hormonal therapy of male hypogonadism. Endocrinology and Metabolism Clinics of North America 22 857-875.

Meikle AW, Mazer NA, Moellmer JF, Stringham JD, Tolman KG, Sanders SW \& Odell WD 1992 Enhanced transdermal delivery of testosterone across non-scrotal skin produces physiological concentrations of testosterone and its metabolites in hypogonadal men. Journal of Clinical Endocrinology and Metabolism 74 623-628. 
Meikle AW, Arver S, Dobs AS, Sanders SW, Rajaram L Mazer NA 1996 Pharmacokinetics and metabolism of a permeation-enhanced testosterone transdermal system in hypogonadal men: influence of application site - a clinical research center study. Journal of Clinical Endocrinology and Metabolism 81 1832-1840.

Parker S \& Armitage M 1999 Experience with transdermal testosterone replacement therapy for hypogonadal men. Clinical Endocrinology 50 57-62.

Place VA \& Nichols KC 1991 Transdermal delivery of testosterone with Testoderm to provide a normal circadian pattern of testosterone. Annals of the New York Academy of Sciences $\mathbf{6 1 8}$ 441-449.

Physician's Desk Reference 2000 edn 54, pp 515-518, 3170-3172. Montvale, NJ, USA: Medical Economics Company.

Rolf C, Gottschalk I, Behre HM, Rauch C, Thyroff U \& Nieschlag E 1999 Pharmacokinetics of new testosterone transdermal therapeutic systems in gonadotropin-releasing hormone antagonist-suppressed normal men. Experimental and Clinical Endocrinology and Diabetes 107 63-69.

Snyder PJ, Peachey H, Berlin JA, Hannoush P, Haddad G, Dlewati A, Santana J, Loh L, Lenrow DA, Holmes JH, Kapoor SC,
Atkinson LE \& Strom BL 2000 Effects of testosterone replacement in hypogonadal men. Journal of Clinical Endocrinology and Metabolism 85 2670-2677.

Wang C, Berman N, Longstreth JA, Chuapoco B, Hull L, Steiner B, Faulkner S, Dudley RE \& Swerdloff RS 2000a Pharmacokinetics of transdermal testosterone gel in hypogonadal men: application of gel at one site versus four sites: a general clinical research center study. Journal of Clinical Endocrinology and Metabolism 85 964-969.

Wang C, Swerdloff RS, Iranmanesh A, Dobs A, Snyder PJ, Cunningham G, Matsumoto AM, Weber T \& Berman N 2000 b Transdermal testosterone gel improves sexual function, mood, muscle strength, and body composition parameters in hypogonadal men. Journal of Clinical Endocrinology and Metabolism 85 2839-2853.

Yu Z, Gupta SK, Hwang SS, Kipnes MS, Mooradian AD, Snyder PJ \& Atkinson LE 1997 Testosterone pharmacokinetics after application of an investigational transdermal system in hypogonadal men. Journal of Clinical Pharmacology 37 1139-1145.

Received 24 May 2002

Accepted 30 August 2002 